\title{
CHANGES IN PARAMETERIZATIONS OF REGIONAL CLIMATE MODEL REGCM4.4.5: THE ROLE OF LAND COVER ON REGIONAL CLIMATE OVER MEDITERRANEAN
}

\author{
Velikou K. ${ }^{1}$, Tolika K. ${ }^{1}$ and Anagnostopoulou Ch. ${ }^{1}$ \\ ${ }^{1}$ Aristotle University of Thessaloniki, School of Geology, Department of Meteorology and Climatology, \\ 54124,Thessaloniki, Greece,kvelikou@geo.auth.gr,diatol@geo.auth.gr,chanag@geo.auth.gr
}

\begin{abstract}
A parameter that affects significantly the local, regional and global climate system is land cover and the changes that may occur to it. During winter season, heavy precipitation assists vegetation growth of Mediterranean forests and woodlands, whereas during summer, absence of precipitation and severe heat waves result to arid and semiarid vegetation. For that reason, it was quite interesting to track the changes that may occur in the climate of the Mediterranean region due to land cover/land use changes on regional climate over the Mediterranean region. The main objective of the study is the assessment of the impacts of land cover/land use changes on regional climate over the Mediterranean region. The examined regional climate model used in the study is RegCM4.4.5. Its spatial resolution is $25 \times 25 \mathrm{~km}$ and different simulations were performed with changes in land cover/land use for the time period 1981-1990. The different simulated data were compared in order to examine the modifications that occur from land cover/land use changes in evapotranspiration and surface albedo to direct and diffuse radiation in the domain of study.
\end{abstract}

Keywords: evapotranspiration, surface albedo, diffuse, direct, CORINE 2000.

\section{Пєрí $\eta \psi \eta$}

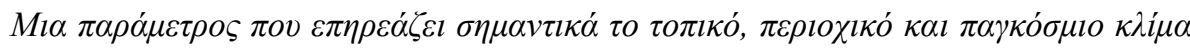

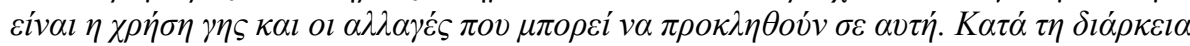

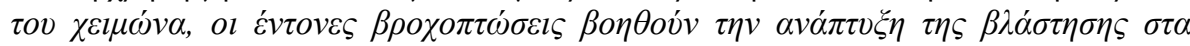

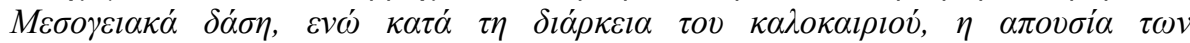

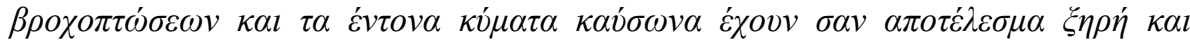

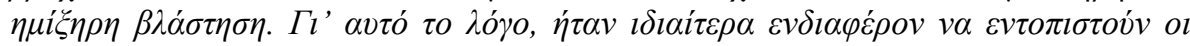

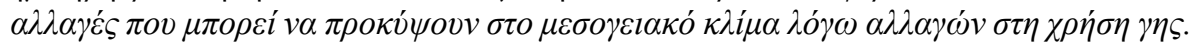

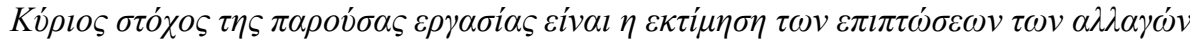

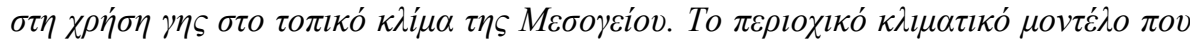

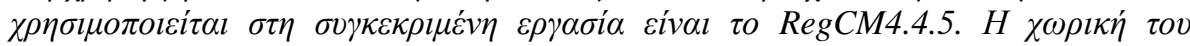

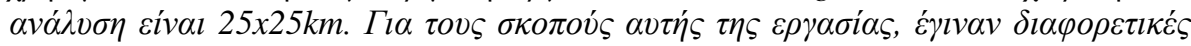

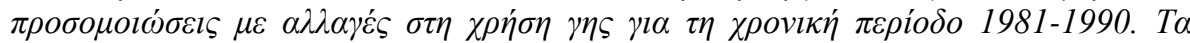

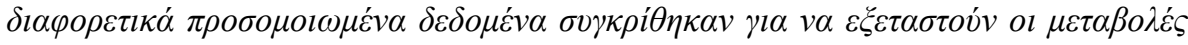

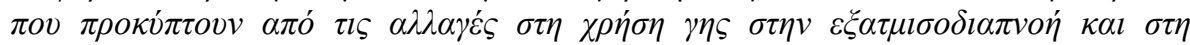

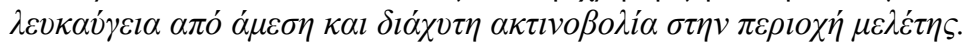

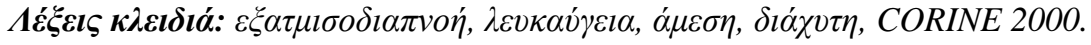




\section{Introduction}

A parameter that has an important role in the local, regional and global climate system is land cover and the changes that may occur to it (Anav et al., 2010). Land cover/Land use changes affect significantly the surface albedo, fluxes of radiation and momentum, heat, water vapor, carbon dioxide and other trace gases, aerosols and dust, and turbulence in the boundary layer (Halder et al., 2015). When we refer to "land cover" we are referring to the physical and biological cover of land surface (water, vegetation, bare soil, artificial structures), whereas with the term "land use" we are also talking about the interaction of human activities (agriculture, forestry etc.) (Ellis, 2013).

During winter season, heavy precipitation assists vegetation growth of Mediterranean forests and woodlands, whereas during summer, absence of precipitation and severe heat waves result to arid and semiarid vegetation (Velikou et al., 2014). For that reason, it was quite interesting to track the changes that may occur in the climate of the Mediterranean due to land cover/land use changes on regional climate over the Mediterranean region.

\section{Data and Methodology}

\subsection{Data}

The examined regional model is RegCM4.4.5, which is a hydrostatic, compressible, sigma-p vertical coordinate model (Giorgi et al., 1993a, b; Elguindi et al., 2014). Its dynamical core is similar to that of the hydrostatic version of Mesoscale Model version 5 (MM5) (Grell et al., 1994). Its spatial resolution is $25 \times 25 \mathrm{~km}$. In this study we used data for evapotranspiration, surface albedo to direct shortwave radiation and surface albedo to diffuse shortwave radiation. These parameters are generally connected to land cover/land use. Evapotranspiration is the sum of evaporation from the Earth's land and ocean surface to the atmosphere and plant transpiration, whereas surface albedo is the fraction of the incident sunlight that the surface reflects (Coakley, 2003).

\subsection{Methodology}

Different simulations were performed with changes in land cover/land use for the time period 19811990 (Figure 1). More specifically, we used the model's default land cover/land use types and CORINE 2000 land cover data. In these simulations ERA-INTERIM data were utilized for sea surface temperature (SST) and initial and boundary conditions (ICBC) in order to "run" the latest version of the regional climate model (RegCM4.4.5.1).

The different simulated data were processed on a seasonal basis and the differences between the CORINE 2000 land cover/land use and the model's default land cover/land use were calculated, mapped and compared. In order to find the statistical significance of these differences the Student's t-test was performed (Wilks, 2006).

\subsubsection{Model's Default Land Cover/Land Use (BATS)}

Biosphere-Atmosphere Transfer Scheme (BATS) is a surface package which describes the role of vegetation and interactive soil moisture in modifying the surface-atmosphere exchanges of momentum, energy and water vapour (Dickinson et al., 1993; Elguindi et al., 2014). It divides land cover in 20 vegetation types according to soil texture and soil colour.

\subsubsection{CORINE Land Cover Project}

The main objective of the CORINE (Coordination of information on the environment) program of the European Commission is to gather, coordinate and ensure the consistency of information on the state of the environment and natural resources. The land cover project (CLC) is part of the CORINE program and is intended to provide consistent localized geographical information on the land cover. It is produced by the European Environmental Agency (EEA) and its member countries and is based 
on the results of IMAGE2000, a satellite imaging program undertaken jointly by the Joint Research Centre of the European Commission and the EEA (http://www.eea.europa.eu/).

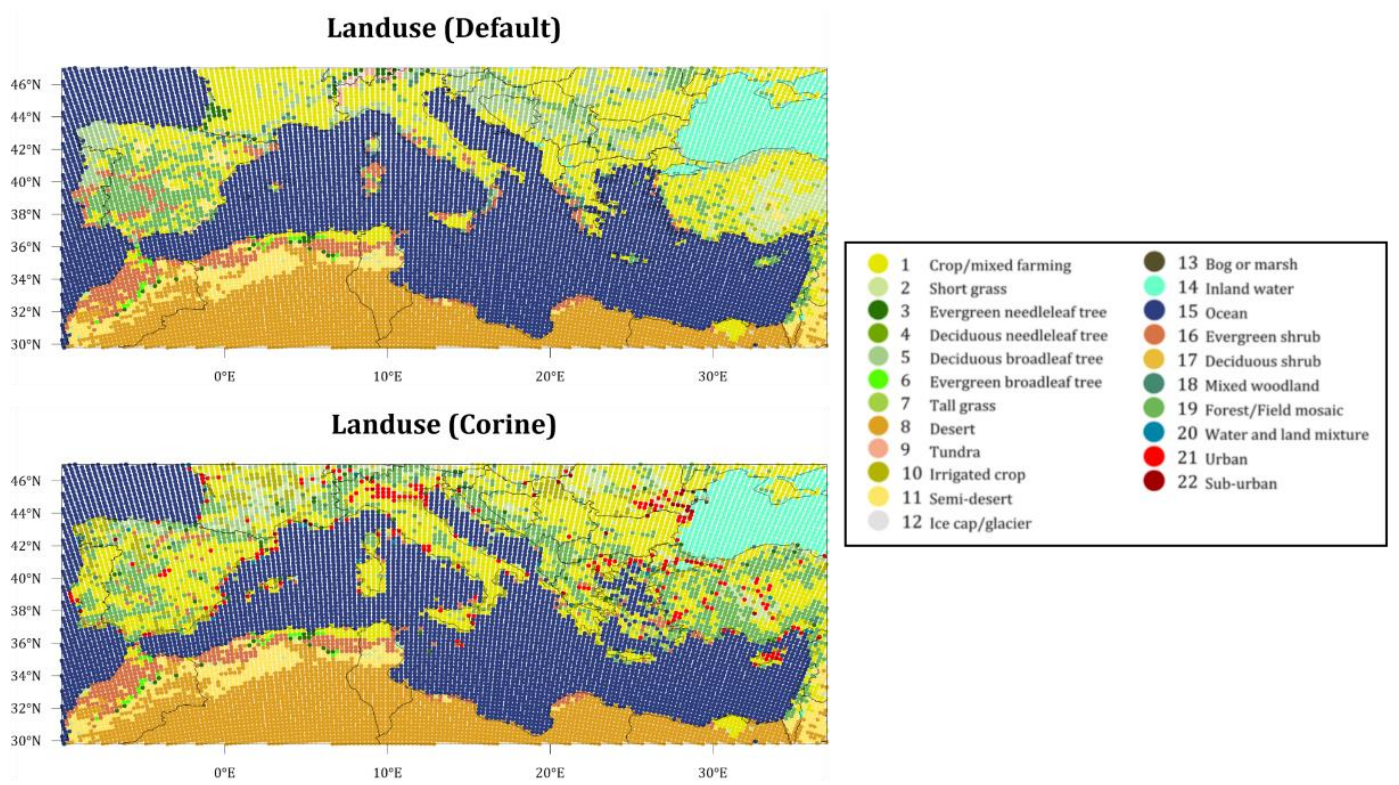

Figure 1 - Simulation domain and land cover types from the different simulations.

\section{Results}

\subsection{Evapotranspiration}

Evapotranspiration Differences Winter 1981-1990

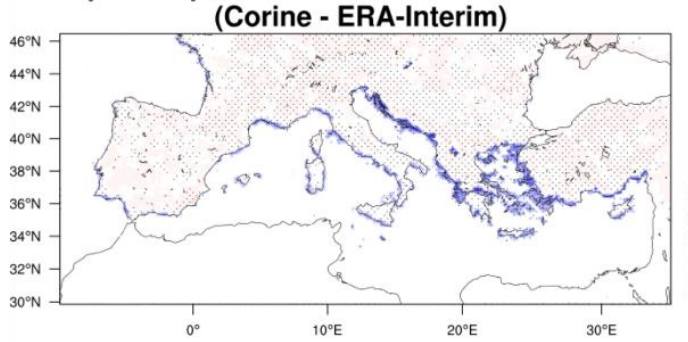

Evapotranspiration Differences Spring 1981-1990

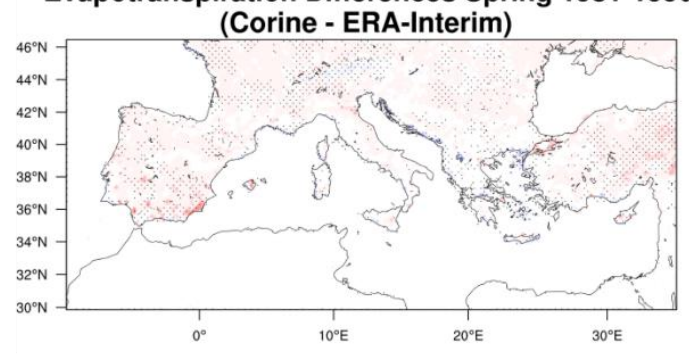

Evapotranspiration Differences Summer 1981-1990

Evapotranspiration Differences Autumn 1981-1990
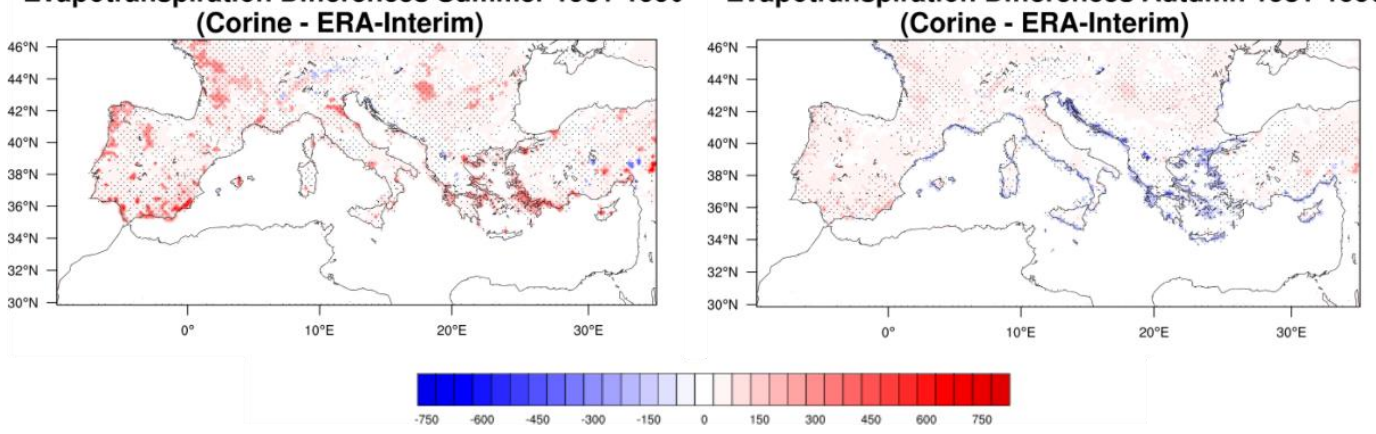

Figure 2 - Seasonal differences in evapotranspiration between the simulation with CORINE 2000 land cover and the simulation with the model's default land cover for the time period 1981-1990. The statistical significance is shown with dots. 
Regarding the changes in evapotranspiration due to changes in the model's default land cover/land use, the most significant decrease is observed during winter and autumn mainly in the coastal areas, whereas an intense increase of this parameter is observed during summer in coastal areas and the mainland of the Iberian Peninsula and central Europe (Figure 2).

This may be due to the fact that CORINE 2000 has more information about land cover/land use in the coastal areas and island regions compared with the model's default land cover/land use. Furthermore, the differences in the vegetation types and the occurrence of urban and sub-urban activity between the CORINE 2000 and the model's default land cover/land use, resulting to changes in the rate of transpiration and evaporation, can explain the significant increase and decrease of evapotranspiration in inland, coastal areas and island regions. In the mainland, throughout the year, a small but significant increase of the parameter is observed.

\subsection{Surface Albedo to Direct and Diffuse Shortwave Radiation}

Regarding surface albedo to direct shortwave radiation, the main modification due to land cover/land use changes occur mainly in the Alps. This is observed in all examined seasons. More specifically, a decrease of the surface albedo is observed in the side of the French Alps, whereas in the central eastern part an increase of the parameter is observed (Figure 3). For the rest of Europe, a small increase of surface albedo is evident, whereas in the eastern part of Turkey a small decrease of the parameter is observed, mainly in winter and spring. This is a result of the different reflectivity and absorption efficiency of radiation from the vegetation that is provided by CORINE 2000 compared to the model's default vegetation. Analogous were the results in the case of surface albedo to diffuse shortwave radiation (Figure 4).

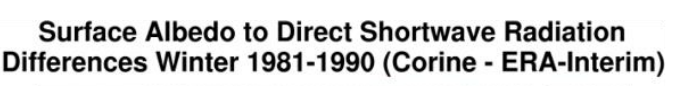

Surface Albedo to Direct Shortwave Radiation
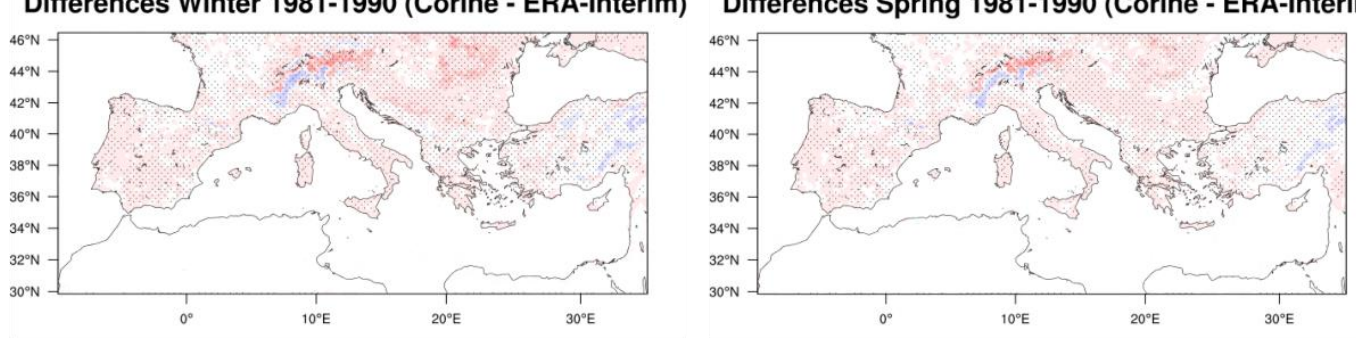

Surface Albedo to Direct Shortwave Radiation

Surface Albedo to Direct Shortwave Radiation Differences Summer 1981-1990 (Corine - ERA-Interim)
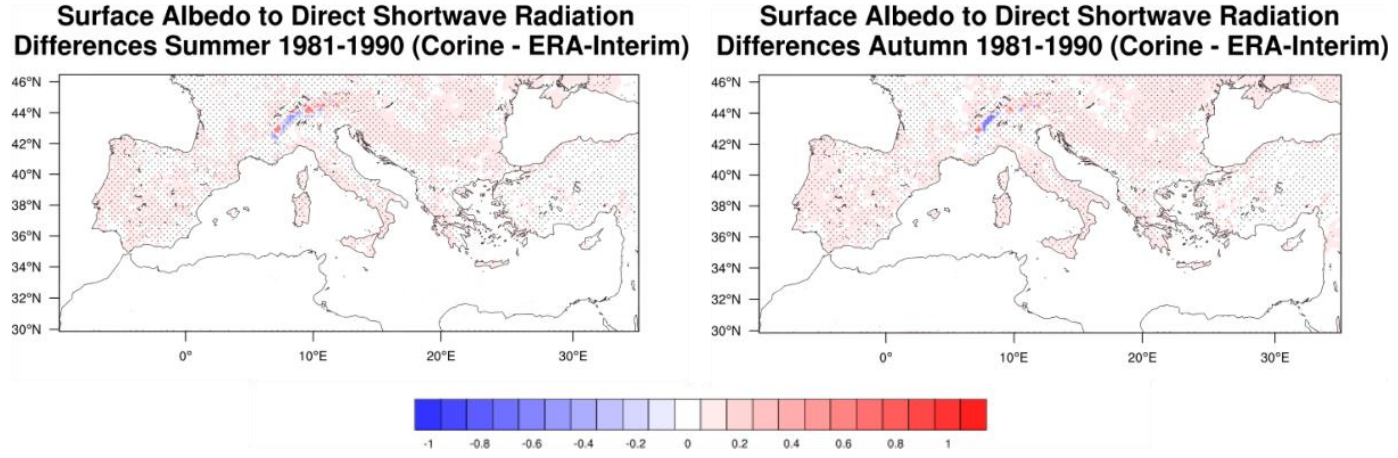

Figure 3 - Seasonal differences in surface albedo to direct shortwave radiation between the simulation with CORINE 2000 land cover and the simulation with the model's default land cover for the time period 1981-1990. The statistical significance is shown with dots. 
Surface Albedo to Diffuse Shortwave Radiation Differences Winter 1981-1990 (Corine - ERA-Interim)

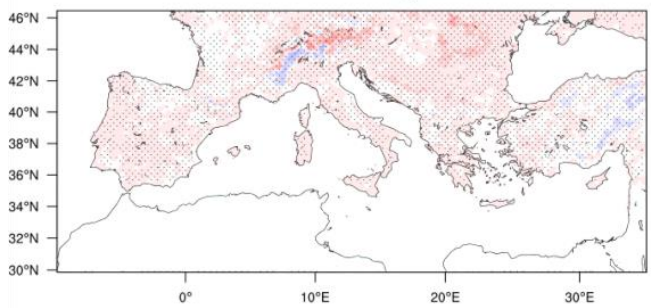

Surface Albedo to Diffuse Shortwave Radiation Differences Summer 1981-1990 (Corine - ERA-Interim)

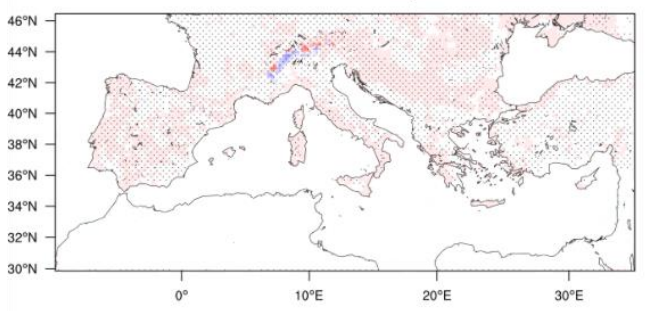

Surface Albedo to Diffuse Shortwave Radiation Differences Spring 1981-1990 (Corine - ERA-Interim)

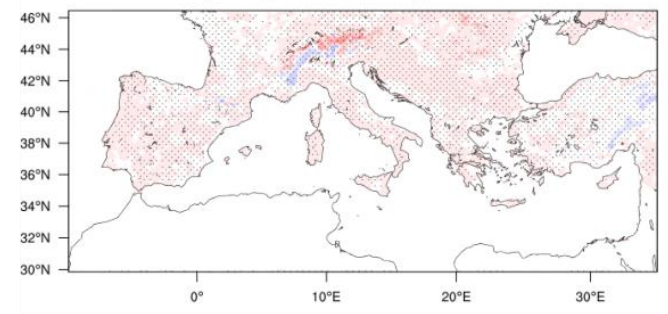

Surface Albedo to Diffuse Shortwave Radiation Differences Autumn 1981-1990 (Corine - ERA-Interim)

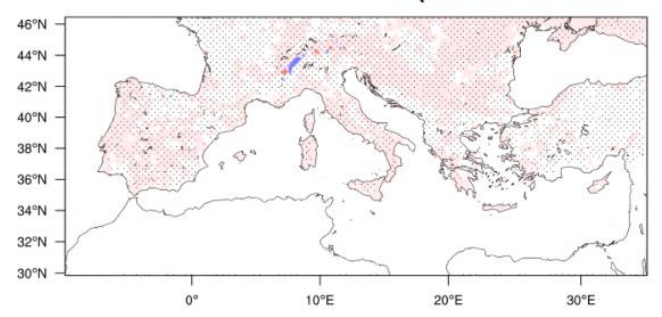

Figure 4 - Seasonal differences in surface albedo to diffuse shortwave radiation between the simulation with CORINE 2000 land cover and the simulation with the model's default land cover for the time period 1981-1990. The statistical significance is shown with dots.

\section{Conclusions}

In this study we applied the latest version of a regional climate model (RegCM4.4.5) in order to simulate the changes and the variability in evapotranspiration and surface albedo to direct and diffuse shortwave radiation under two different land cover/land use parameterizations. The selected domain of interest is the Mediterranean region and the simulations covered the time period 19811990. The first simulation used the model's default land cover/land use and the second used land cover/land use data taken from the CORINE Land Cover European Union Programme (http://www.eea.europa.eu/) (Figure 1). The results from the simulation with the CORINE 2000 land cover/land use were compared with the corresponding results from the simulation with the model's default land cover/land use in the area of study.

According to the analysis of the results, the most significant changes in evapotranspiration are observed during winter and autumn in the coastal areas of the Mediterranean region, where evapotranspiration presents a decrease. Additionally, significant increase of the same parameter is observed during summer not only in the coastal areas but also in the mainland of the Iberian Peninsula and central Europe.

In the case of surface albedo to direct and diffuse shortwave radiation, the results are quite similar in both cases. More specifically, the most significant changes are observed in the Alps, where throughout the year surface albedo shows a decrease in the French Alps. Conversely, in central eastern Alps surface albedo seems to increase. These changes are more evident during winter and spring.

Changes in land cover/land use lead to different vegetation types and as a result this differences affects evaporation and transpiration rates as well as the reflectivity and absorption efficiency of the different surfaces. The hydrology, the agriculture, the forests of a region can be influenced not only 
by climate parameters but also by changes in land cover/land use, which may occur from natural reasons or from human interactions (e.g. land use or water management).

As future work, more parameters should be studied and also a comparison with real data should be performed in order to be able to conclude about the most appropriate land cover/land use scheme that should be used with regional climate model RegCM.

\section{References}

Anav, A., Ruti, P.M., Artale, V. and Valentini, R., 2010. Modelling the Effects of Land-Cover Changes on Surface Climate in the Mediterranean Region, Climate Research, 41, 91-104.

Coakley, J.A. Jr., 2003. Reflectance and Albedo. In: Holton, J.R. and Curry J.A., eds., Encyclopedia of the Atmosphere, Academic Press, 1914-1923, doi: 10.1016/B0-12-227090-8/00069-5.

Dickinson, R.E., Henderson-Sellers, A. and Kennedy, P.J., 1993. Biosphere-Atmosphere Transfer Scheme (BATS) Version 1e as coupled to the NCAR community climate model, Technical Note, NCAR/TN-387+STR, 72 pp.

Elguindi, N., Bi, X., Giorgi, F., Nagarajan, B., Pal, J., Solmon, F., Rauscher, S., Zakey, A., O’ Brien, T. and Giuliani, G., 2014. Regional Climate Model RegCM User Manual Version 4.4, International Centre for Theoretical Physics (ICTP) - Trieste, Italy.

Ellis, E., 2013. Land-Use and Land-Cover Change. Retrieved from: http://www.eoearth.org/view/article/154143.

Giorgi, F., Marinucci, M.R. and Bates, G.T., 1993a. Development of a Second Generation Regional Climate Model (RegCM2). Part I: Boundary Layer and Radiative Transfer Processes, Monthly Weather Review, 121, 2794-2813.

Giorgi, F., Marinucci, M.R., Bates, G.T. and DeCanio, G., 1993b. Development of a Second Generation Regional Climate Model (RegCM2). Part II: Convective Processes and Assimilation of Lateral Boundary Conditions, Monthly Weather Review, 121, 2814-2832.

Grell, G., Dudhia, J. and Stauffer, D.R., 1994. A Description of the Fifth Generation Penn State/NCAR Mesoscale Model (MM5), Technical Note, NCAR/TN-398+STR, 121 pp.

Halder, S., Sah, S.K., Dirmeyer, P.A., Chase, T.N. and Goswami, B.N., 2015. Investigating the impact of land-use land-cover change on Indian summer monsoon daily rainfall and temperature during 1951-2005 using a regional climate model, Hydrology and Earth System Sciences Discussions, 12, 6575-6633.

Velikou, K., Anagnostopoulou, C. and Tolika, K., 2014. Impacts of Topography and Land Cover Changes on Regional Climate over the Eastern Mediterranean, European Geosciences Union General Assembly, Vienna - Austria, 27 April - 2 May, EGU2014-761.

Wilks, D.S., 2006. Statistical Methods in the Atmospheric Sciences, USA, Elsevier Academic Press, 138-140, Second Edition. 